
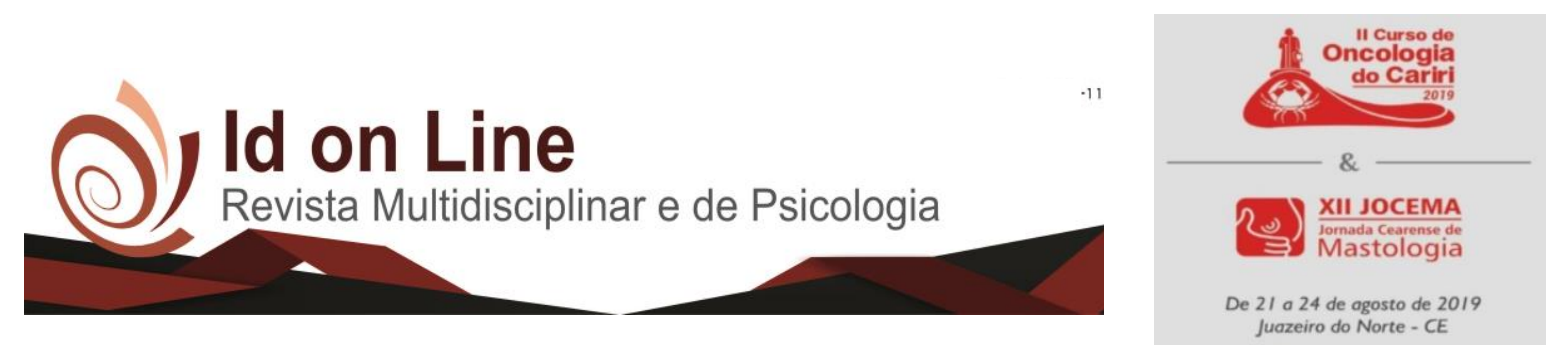

DOI: 10.14295/idonline.v13i46.1990

Resumo

\title{
A MORTALIDADE POR CÂNCER DE PÂNCREAS NA MICRORREGIÃO DO CARIRI
}

\author{
MENDES, Ana Carla da Silva ${ }^{1}$; MENDES, Isabelle Lima ${ }^{2}$; SOARES, Laryza Souza \\ OLIVEIRA, Palloma Rodrigues Vieira ${ }^{4}$; XIMENES, Priscila Arrais Rolim Aragão ${ }^{5}$; \\ LACERDA, Virgínia Maia ${ }^{6}$
}

Introdução: O Câncer de Pâncreas, no Brasil, é responsável por 2\% de todos as neoplasias diagnosticadas e por $4 \%$ de óbitos causados por neoplasias malignas. $90 \%$ dos casos tem como tipo histológico o adenocarcinoma, a maior parte diagnosticada após os 65 anos, $\mathrm{O}$ aumento da incidência de CA de pâncreas associa-se ao envelhecimento, exacerbação do consumo de gorduras, obesidade, DMII, sedentarismo, álcool, e, sobretudo, tabaco. O CA de pâncreas, em 90\% dos casos, já é descoberto avançado localmente ou com metástases à distância, desse modo, a sobrevida de 5 anos somente ocorre em $8 \%$ do casos. Objetivo: Analisar perfil epidemiológico do câncer de pâncreas na Microrregião do cariri, entre os anos de 2008 a 2018. Metodologia: Foi realizada uma pesquisa retrospectiva, descritiva, quantitativa, de caráter exploratório no período de 2008 a 2018, com registros obtidos na base de dados DataSus, comparando os dados referentes a mortalidade de câncer de pâncreas neste período. Como estratégias de pesquisa, foram definidos os seguintes pontos: microrregião IBGE: 23032 Cariri, capítulo do CID-10: II. Neoplasias (tumores), lista de morbidade CID-10: Neoplasia Maligna do Pâncreas; Todas as faixas etárias, do sexo masculino e feminino, no período: 2008-2018. Resultados: De acordo com os dados do DataSus, de 2008 a 2018, a taxa de mortalidade por câncer de pâncreas na microrregião do cariri foi equivalente a 37. A idade em que houve mais óbitos foi entre 60 a 69 anos, correspondendo a $27,03 \%$ do total. No Brasil, durante o período de 2005-2012, a letalidade foi maior em pessoas com 70 anos ou mais, e houve um aumento de mortalidade nas pessoas entre 50-69 anos. No Cariri, a mortalidade total em homens foi de 18 casos e em mulheres foi de 19 casos. No Canadá, as taxas de mortalidade entre 1992 e 2009 diminuíram em homens e permaneceu estável em mulheres. No Taiwan, taxa de mortalidade aumentou de 0,30 a 0,37 por 100.000 para os menores de 50 e de 3,18 para 3,76 por 100.000 para aqueles com mais de 50, a taxa de mortalidade foi também maior em homens 5 a cada 10000. Conclusão: Embora o estudo seja limitado, em virtude da fonte de dados, DataSus, não abordar tipo histológico do tumor, grau do tumor no diagnóstico, se as pessoas que vieram a óbito tinham sido submetidas a alguma forma de tratamento e quais eram os hábitos de vidas desses indivíduos, pode-se afirmar que é de suma importância o tratamento e o diagnóstico precoces, bem como, a adesão de hábitos de vida saudáveis.

Palavras-chave: Câncer de Pâncreas; Mortalidade; Epidemiologia;

\footnotetext{
${ }^{1}$ Autora; Acadêmica do curso de medicina na Faculdade de Medicina Estácio de Juazeiro do Norte; e-mail: anademariaedejesus@gmail.com. ${ }^{2}$ Orientadora; Docente na Faculdade de Medicina Estácio de Juazeiro do Norte; e-mail: isabellelimamendes@hotmail.com.

${ }^{3}$ Coautora; Acadêmica do curso de medicina na Faculdade de Medicina Estácio de Juazeiro do Norte; e-mail: laryzasouza@gmail.com.

${ }^{4}$ Coautora; Acadêmica do curso de medicina na Faculdade de Medicina Estácio de Juazeiro do Norte; e-mail: palloma.oliver29@gmail.com

${ }^{5}$ Coautor; Acadêmica do curso de medicina na Faculdade de Medicina Estácio de Juazeiro do Norte; e-mail: priscilaximenes@ gmail.com

${ }^{6}$ Coautora; Acadêmica do curso de medicina na Faculdade de Medicina Estácio de Juazeiro do Norte; e-mail: maia_lacerda@hotmail.com
} 


\section{Referências:}

INSTITUTO NACIONAL DO CÂNCER. Câncer de Pâncreas. Brasil, 2018. Disponível em: <https://www.inca.gov.br/tipos-de-cancer/cancer-de-pancreas>. Acesso em: 03.08.2019.

JIA, X. et al. Pancreatic Cancer Mortality in China Characteristics and Prediction. Wolters Kluwer Health, Inc. 2018

SEOANE-MATO, D. et al.Long-term trends in pancreatic cancer mortality in Spain (1952-2012). BMC Cancer, 2018.

SOUZA, L.M.P. et al.Pancreatic Cancer Incidence and Lethality Rates in Brazil An Ecological Study. Wolters Kluwer Health, Inc. Volume 46, Number 5, May/June 2017.

TSENG, C.M. et al.Incidence and mortality of pancreatic cancer on a rapid rise in Taiwan, 19992012. Cancer Epidemiology, 2017. 